\title{
Response to the COVID-19 Outbreak in Urban Settings in China
}

\author{
Zhao Ni $\mathbb{D}$ - Eli R. Lebowitz • Zhijie Zou • Honghong Wang • Huaping Liu • Roman \\ Shrestha • Qing Zhang • Jianwei Hu • Shuying Yang • Lei Xu • Jianjun Wu • Frederick L. \\ Altice
}

\begin{abstract}
The COVID-19 outbreak in China was devastating and spread throughout the country before being contained. Stringent physical distancing recommendations and shelter-in-place were first introduced in the hardest-hit provinces, and by March, these recommendations were uniform throughout the country. In the presence of an evolving and deadly pandemic, we sought to investigate the impact of this pandemic on individual well-being and prevention practices among Chinese urban residents. From March 2-11, 2020, 4607 individuals were recruited from 11 provinces with varying numbers of COVID-19 cases using the social networking app WeChat to complete a brief, anonymous, online survey. The analytical sample was restricted to
\end{abstract}

Z. Ni $(\bowtie) \cdot$ E. R. Lebowitz $\cdot$ R. Shrestha $\cdot$ F. L. Altice

School of Medicine, Yale University, New Haven, Connecticut, USA

e-mail: zhao.ni@yale.edu

Z. Zou $(\bowtie) \cdot$ Q. Zhang

School of Health Sciences, Wuhan University, Wuhan, Hubei,

China

e-mail: zouzhijiehope@163.com

H. Wang

Xiangya School of Nursing, Central South University, Changsha, Hunan, China

H. Liu

School of Nursing, Peking Union Medical College, Beijing, China

R. Shrestha

Institute for Collaboration on Health, Intervention, \& Policy,

University of Connecticut, Storrs, Connecticut, USA
2551 urban residents. Standardized scales measured generalized anxiety disorder (GAD), the primary outcome. Multiple logistic regression was conducted to identify correlates of GAD alongside assessment of community practices in response to the COVID-19 pandemic. We found that during the COVID-19 pandemic, the recommended public health practices significantly $(p<0.001)$ increased, including wearing facial mask, practicing physical distancing, handwashing, decreased public spitting, and going outside in urban communities. Overall, $40.3 \%$ of participants met screening criteria for GAD and $49.3 \%, 62.6 \%$, and $55.4 \%$ reported that their work, social life, and family life were interrupted by anxious feelings, respectively. Independent correlates of

J. Hu

College of Nursing, Xi'an Medical University, Xi'an, Shaanxi,

China

\section{S. Yang}

Hohhot Vocational College, Hohhot, Inner Mongolia, China

L. Xu

School of Nursing, Fudan University, Shanghai, China

J. Wu

Gansu University of Chinese Medicine, Lanzhou, Gansu, China

F. L. Altice

West China Hospital/West China School of Nursing, Sichuan University, Chengdu, Sichuan, China

F. L. Altice

School of Public Health, Yale University, New Haven, Connecticut, USA 
having anxiety symptoms included being a healthcare provider $(\mathrm{aOR}=1.58, p<0.01)$, living in regions with a higher density of COVID-19 cases $(\mathrm{aOR}=2.13$, $p<0.01)$, having completed college $(\mathrm{aOR}=1.38, p=$ $0.03)$, meeting screening criteria for depression $(\mathrm{aOR}=$ $6.03, p<0.01)$, and poorer perceived health status $(\mathrm{aOR}=1.54, p<0.01)$. COVID-19 had a profound impact on the health of urban dwellers throughout China. Not only did they markedly increase their self- and community-protective behaviors, but they also experienced high levels of anxiety associated with a heightened vulnerability like depression, having poor perceived health, and the potential of increased exposure to COVID-19 such as living closer to the epicenter of the pandemic.

Keywords Coronavirus · COVID-19 - Anxiety · China · Urban $\cdot$ Health behavior $\cdot$ Social life $\cdot$ Global health

\section{Introduction}

The novel coronavirus disease 2019 (COVID-19) pandemic first rapidly spread throughout China, and by August 19, 2020, it had manifested in 188 countries with 22,244,179 confirmed cases and 783,525 deaths worldwide [1]. In the absence of effective vaccines or treatments, public health authorities have relied upon sheltering in place (self-quarantine at home), physical distancing in public settings, handwashing, and wearing facial masks to prevent further spread $[2,3]$. Without fully understanding its transmission, risk of progression, and widespread death from COVID-19, panic and even hysteria were common [4]. The World Health Organization made public the COVID-19 outbreak in January 2020 [5], and observed that the outbreaks were more severe in urban settings with a higher density of people [6]. Consequently, Chinese residents increasingly complied with recommended containment measures that are necessary under this time of crisis, but those measures could disrupt their work and social and family life. Also, during the pandemic, many urban dwellers remained relatively segregated within their neighborhoods, and this negatively impacted their psychological well-being $[7,8]$.

Anxiety symptoms among urban dwellers dealing with a volatile COVID-19 pandemic, however, have not been broadly examined since it does not affect everyone equally. Over the past 18 years, various settings have reacted to new infectious disease epidemics like SARS, MERS, and Ebola, and though none of these developed into worldwide pandemic, understanding factors that may undermine the health of the community is important for future public health disaster planning efforts. We, therefore, conducted a nationwide online survey of people in China to identify those factors associated with anxiety from COVID-19 and focused only on urban dwellers here, since they experienced COVID-19 differently than their non-urban counterparts.

\section{Methods}

Study Design and Participants

We conducted baseline, online survey with 4607 participants living in China; two additional waves are underway. The participant inclusion criteria included (1) $\geq$ 18 years old; (2) living in mainland China; (3) able to read Chinese; and (4) having access to WeChat (the largest social networking app in China). Participants would be excluded if they did not electronically sign the consent form or submit the baseline questionnaire. All recruited participants were asked to complete a baseline survey over 10 days from March 2 to 11 , 2020. A total of 4607 individuals from 11 provinces, with the varied impact of the COVID-19 pandemic, completed the online survey. The analytical sample was restricted to 2551 urban residents who completed the enrollment survey. In this article, the time point of COVID-19 outbreak refers to January 23, 2020, when Wuhan City was placed in quarantine. The study protocol was approved by the Institutional Review Board of Yale University and received ethical approval from Wuhan University.

\section{Study Procedures}

In this study, we used a modified snowball recruitment strategy where 11 participants (seeds) were recruited, one each from the 11 representative provinces in China. Eleven representative provinces were selected from mainland China based on two criteria: (1) being in one of mainland China's six social-economic regions as classified by the National Bureau of Statistics of China-North (Beijing, Tianjin, Hebei, Shanxi, Inner Mongolia), Northeast (Liaoning, Jilin, Heilongjiang), East 
(Shanghai, Jiangsu, Zhejiang, Anhui, Fujian, Jiangxi, Shandong), Central South (Henan, Hubei, Hunan, Guangdong, Guangxi, Hainan), Southwest (Chongqing, Sichuan, Guizhou, Yunnan, Tibet), and Northwest (Shaanxi, Gansu, Qinghai, Ningxia, Xinjiang) [9]; and (2) COVID-19 severity as was categorized by China National Health Commission [10] (diagnosed COVID19 cases $\geq 10,000 ; 1000-9999 ; 100-999$; $\leq 99$ ) based on the percentage of provinces in each stratum in March 2020 (Fig. 1). Using these criteria, we selected the following 11 representative provinces: Beijing, Inner Mongolia, Heilongjiang, Shandong, Henan, Hubei, Hunan, Guizhou, Shaanxi, Gansu, and Xinjiang. Seeds were recruited using convenience sampling method, in which two authors (Zhao and Zhijie) took advantage of their trusted interpersonal relationship with colleagues in the 11 provinces, who were daily active on WeChat, to recruit participants. Specifically, Zhao randomly selected one seed from Beijing, Heilongjiang, Shandong, Hunan, and Xinjiang, respectively. Zhijie selected one seed from Inner Mongolia, Henan, Hubei, Guizhou, Shaanxi, and Gansu, respectively.

To address the impact of the COVID-19 pandemic, the survey was developed and pilot-tested using methods that have been described elsewhere [11]. In brief, standardized scales were used, and responses to COVID-19 were created. After drafting candidate questions, ten experts in the field took the survey and provided feedback to refine the survey. The revised survey was then designed on Questionnaire Star (https://www.wjx.cn/), a professional platform for online surveys [12], and a web link, and a quick response $(\mathrm{QR})$ code was generated. We then pilottested the survey with 32 individuals who accessed the survey from a web link or QR code and sought feedback. Using feedback, we finalized the electronic survey and applied the web-based sampling method to recruit participants after identifying the seed in each province.

The selected 11 seed participants completed the survey and then distributed a flyer that contained recruitment information, QR code, and a link to the online survey among their social network. The distribution of the flyer occurred through WeChat moments ("Peng You Quan" in Chinese) or their WeChat groups ("Wei Xin Qun" in Chinese). Interested individuals who clicked on the link were directed to an eligibility screener. Each eligible participant voluntarily completed an online consent form by acknowledging that they understood the purpose, risks, and benefits of the study prior to completing the survey. On average, participants took 12 minutes to complete the anonymous online survey. The questionnaire was available in both English and Chinese languages and was translated and backtranslated to ensure culture meaning [13].

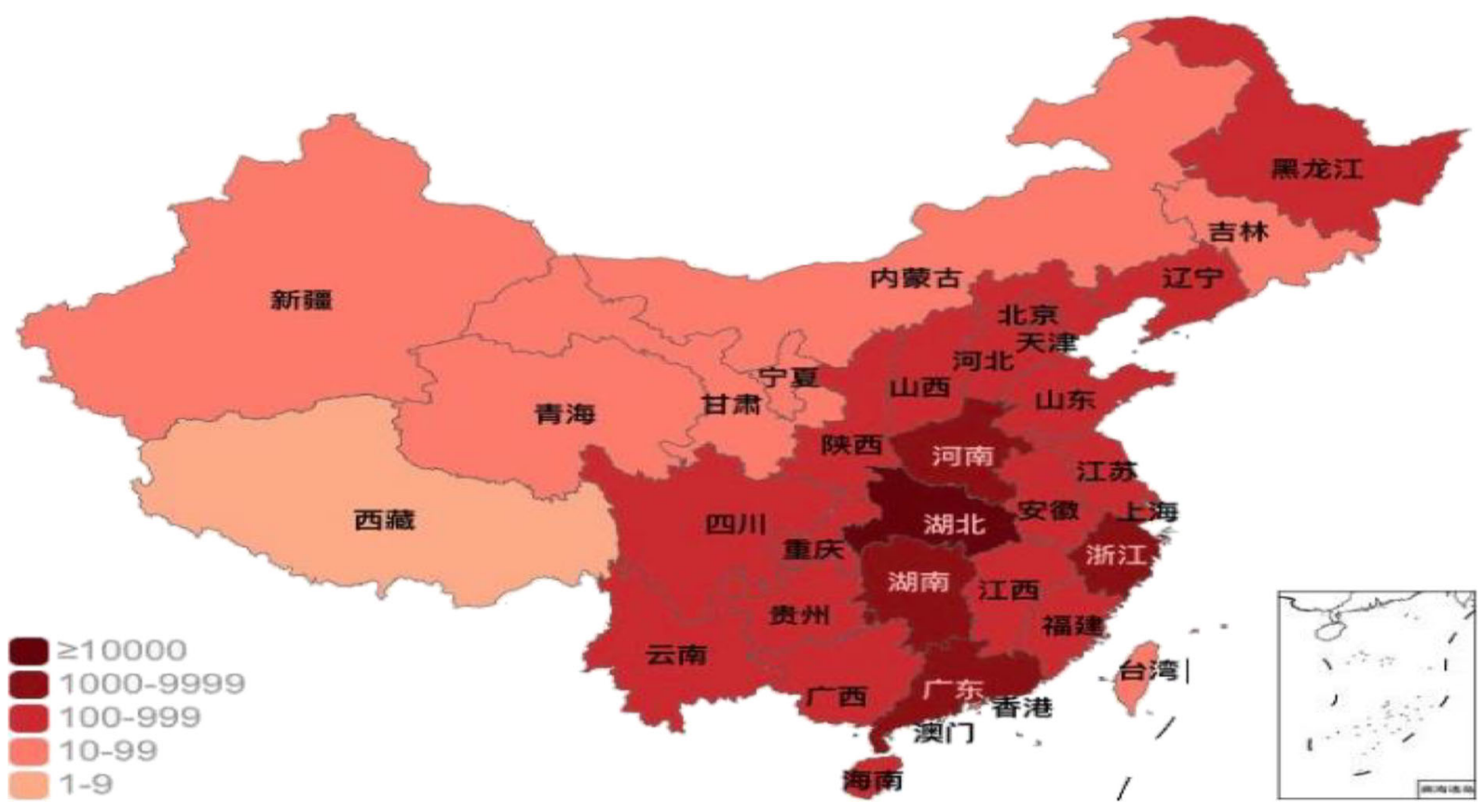

Fig. 1 Chinese provinces with different density of COVID-19 cases. This figure was retrieved from Tencent Health on March 10, 2020 


\section{Study Measures}

Sociodemographic characteristics included age, sex, educational level, income, health, employment, and marital status. Income was stratified based on the relationship to the national levels.

Traveling history in the past 30 days included whether they had traveled after the COVID-19 outbreak and whether they were put in quarantine. Living environment was based on with whom they lived, and the region where they lived, stratified by the density of COVID-19 cases, with Hubei province being the highest. We also measured where participants accessed information pertaining to COVID-19 and what measures that their communities had taken to control COVID-19.

Participants' self-perceived health statuses were measured by the question "How is your current health status?" with a response of "Very good," "Good," "Fair," "Poor," and "Very poor." These answers were dichotomized into "Good" ("Very good" + "Good"), and "Not good" ("Fair" + "Poor" + "Very poor"). In addition, we assessed the frequency of the following health-related behaviors, before and after the COVID19 outbreak, which included wearing face masks, practicing physical distancing, washing hands, spitting, and showering. The questions related to each construct are included in Table 2.

The primary outcome was the presence of anxiety symptoms, which was measured by the Generalized Anxiety Disorder 7-item (GAD-7) scale, which has good reliability, sensitivity, and specificity for measuring anxiety in Chinese populations [14]. Other screening for mental illness included assessment of obsessivecompulsive symptoms using the ObsessiveCompulsive Inventory [15] and depression using the Patient Health Questionnaire-2 [16].

\section{Statistical Analyses}

All data analyses were performed using SAS 9.4 (SAS Institute, Cary, North Carolina, United States). Data were presented using frequencies and means. Chisquare test was used to compare the behaviors of wearing face masks and practicing physical distancing before and after the COVID-19. Student's t test was used to examine differences in handwashing, spitting, going outside, and showering, before and after the outbreak. Logistic regression was used to examine the association between potential explanatory variables and the presence of anxiety. Generalized anxiety disorder (GAD) cutoffs for mild, moderate, and severe symptoms include scores of 5-9, 10-14, and $>15$, respectively. Anxiety was dichotomized for values $>4$, which is associated with the presence of anxiety symptoms. Any variable significant at $p<0.10$ in bivariate analyses were then entered into the multivariate logistic regression model to determine the odds ratio and 95\% confidence intervals for the final model. An additional analysis (Supplementary Data) for moderate to severe anxiety symptoms (cutoff $>9$ ) was also conducted.

\section{Results}

\section{Participant Characteristics}

Most participants (Table 1) were female (68.9\%), in their 30 s $(31.3 \pm 11.9)$, completed a college degree $(89.5 \%)$, and perceived themselves to be in good health status (74.8\%). Nearly $34 \%$ of the participants have an annual income of greater than $¥ 60,000$ (15 times greater than the Chinese poverty threshold [17]; 12 times greater than the international poverty threshold [18]; equivalent to 8571 USD), and $16.0 \%$ of the participants were healthcare providers. Nearly all $(93.1 \%)$ participants were living with families and remained in one city during the 30 days prior to the study. Participants were from regions with different density of COVID-19 cases, $22.8 \%$ of them were from the epicenter-Hubei Province. Nearly half $(47.4 \%)$ of the participants were married. Most participants reported that they did not travel (95.5\%) after the COVID-19 outbreak, and most communities $(93.4 \%)$ had taken strict measures to control COVID-19. Overall, the top three commonly used preventative measures in Chinese urban areas were controlling the entry and exit of people by checking their body temperature at neighborhood buildings, banning gatherings in the community, and cleaning and sanitizing communal spaces (Fig. 2).

Health-Related Behaviors Before and After the COVID-19 Outbreak

The number of participants who wore face masks and practiced physical distancing increased significantly after the COVID-19 outbreak $(p<0.001)$. The frequency of handwashing also increased significantly $(p<0.001)$. 
Table 1 Characteristics of participants $(N=2551)$.

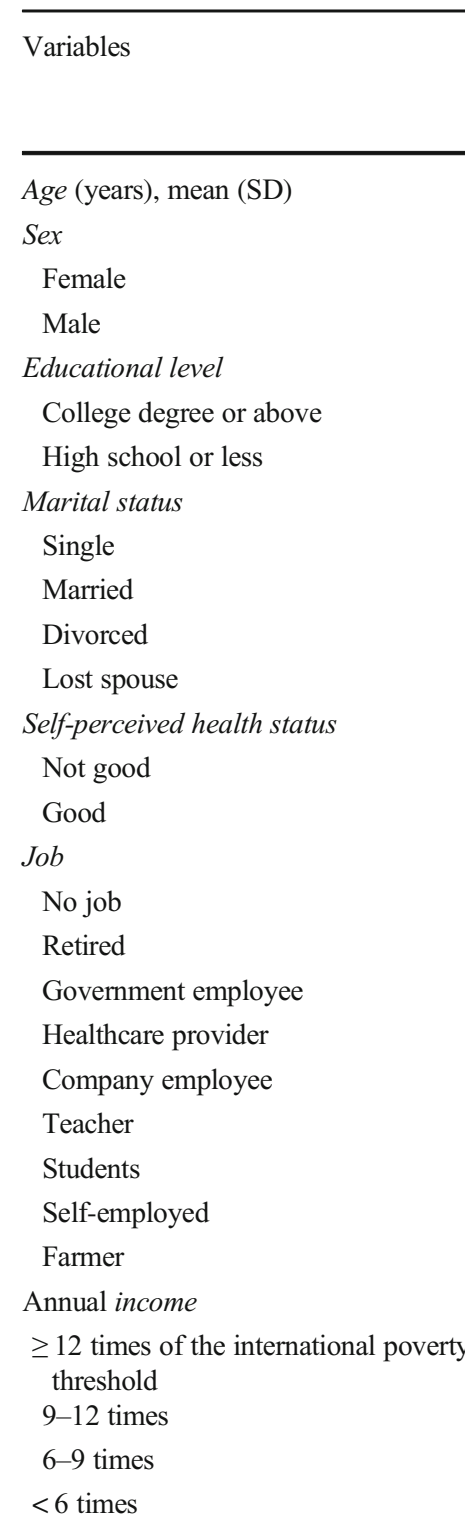

Table 1 (continued)

\begin{tabular}{lll}
\hline Variables & \multicolumn{2}{l}{ Sample } \\
\cline { 2 - 3 } & Frequency & \% \\
\hline Loose & 9 & 0.3 \\
Traveled after the COVID-19 outbreak & & \\
Yes & 116 & 4.6 \\
No & 2435 & 95.5 \\
In quarantine & & \\
Yes & 219 & 8.6 \\
No & 2332 & 91.4 \\
Reasons of being put in quarantine & & \\
Diagnosed with COVID-19 & 2 & 0.1 \\
Has symptoms of COVID-19 & 2 & 0.1 \\
Had been in contact with COVID-19 & 16 & 0.6 \\
Returning hometown from other communities & 199 & 7.8 \\
$\quad$ where there were COVID-19 patients & &
\end{tabular}

Where people learned about updated information of the COVID-19

$\begin{array}{lll}\text { App (WeChat, QQ, NetEase, etc.) } & 2405 & 94.3 \\ \text { Website } & 1713 & 67.2 \\ \text { Radio } & 659 & 25.8 \\ \text { TV } & 1817 & 71.2 \\ \text { Journal } & 231 & 9.1 \\ \text { Family or relatives } & 1293 & 50.7 \\ \text { Friends } & 1083 & 42.5 \\ \text { Colleagues } & 723 & 28.3 \\ \text { Depression } & & \\ \text { Yes } & 381 & 14.9 \\ \text { No } & 2170 & 85.1\end{array}$

Generalized anxiety disorder

$\begin{array}{lll}\text { Mild } & 832 & 32.6\end{array}$

Moderate $\quad 150 \quad 5.9$

$\begin{array}{llll}19.7 & \text { Severe } & 46 & 1.8\end{array}$

$\begin{array}{llll}22.9 & \text { Any } & 1028 & 40.3\end{array}$

$\begin{array}{llll}23.7 & \text { No consistent symptom } & 1523 & 59.7\end{array}$

From regions with different density of COVID-19 cases (March 2020)

Work/schoolwork has been disrupted

$\begin{array}{lll}\text { Yes } & 1258 & 49.3\end{array}$

Hubei ( $\geq 10,000$ cases)

$581 \quad 22.8$

2nd highest region (1000-9999 cases) $\quad 680 \quad 26.7$

3rd highest region (100-999 cases) $\quad 988 \quad 38.7$

Low-density region (1-99 cases) $\quad 302 \quad 11.8$

Living alone

Yes 177

No 2374

6.9

93.1

Measures taken to control COVID-19 in your community

Very strict

1249

49.0

Strict

1133

44.4

Fair

160
No

1293

Social life has been disrupted

Yes

1597

954

Family life/home responsibilities have been disrupted

Yes

$1414 \quad 55.4$

No

1137

44.6

Presence of obsessive-compulsive disorder

Yes

232

9.1

No

2319 


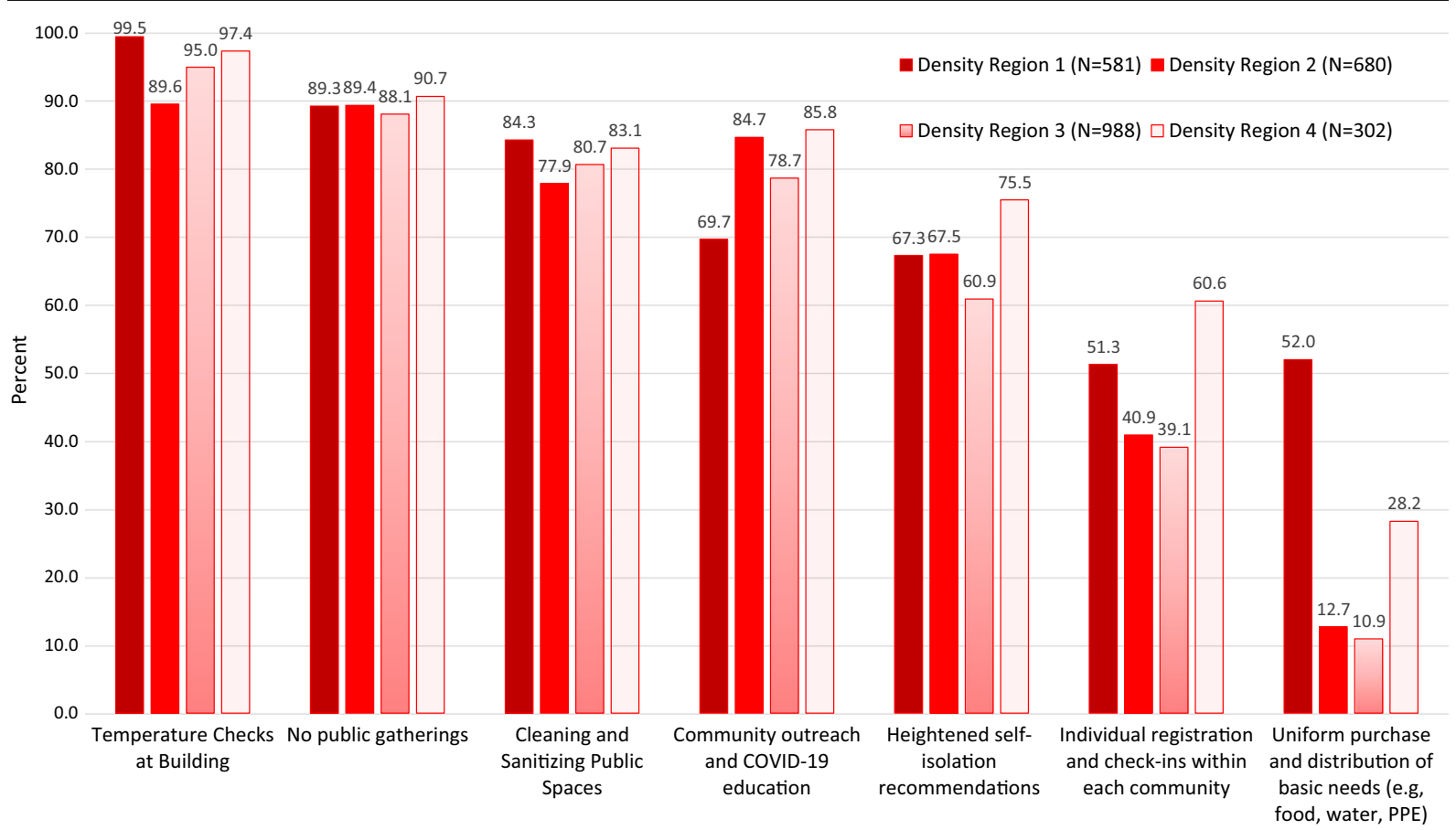

Fig. 2 Countermeasures to preventing COVID-19

The rate of spitting in public places and going outside of one's home decreased significantly $(p<0.001$; Table 2).

\section{Correlates of Having Generalized Anxiety Disorder}

Several independent correlates were associated with having mild, moderate, and severe anxiety symptoms, including poor perceived health status $(\mathrm{aOR}=1.54, p<0.01)$, being a healthcare provider $(\mathrm{aOR}=1.58, p<0.01)$, receiving a college degree or above $(\mathrm{aOR}=1.38, p=0.03)$, living in Hubei (aOR=2.13, $p<0.01$ ), and meeting screening criteria for depression $(\mathrm{aOR}=6.03, p<0.01$; Table 3).

\section{Correlates of Moderate to Severe Generalized Anxiety Disorder}

As shown in Table 4 in the supplementary appendix, poor self-perceived health status $(\mathrm{aOR}=1.73, p<0.01)$, higher frequency of washing hands $(\mathrm{aOR}=1.02, p=$ $0.03)$, living in Hubei $(\mathrm{aOR}=2.85, p<0.01)$, and meeting screening criteria for depression $(\mathrm{aOR}=24.20$, $p<0.01$ ) were independently associated with moderate and severe anxiety symptoms.

\section{Discussion}

The unprecedented COVID-19 pandemic has raised significant public health concerns and has an extended impact on the psychological well-being of society, especially in urban areas most profoundly impacted by the disease. The COVID-19 epidemic unleashed a rapid and unprecedented response by society, in which we report the profound protective response to the COVID-19 outbreak. In response to government guidance and clear messaging, frequency of handwashing and physical distancing practices increased, while venturing outside in crowded urban spaces or spitting in public places decreased. Though public spitting is unlawful in some Chinese cities like Beijing [19], Hangzhou [20], and Tianjin [21], it remains legal and practiced elsewhere; but during COVID-19, such practices markedly reduced. On May 15, 2020, the Chinese Government of Shanxi Province passed China's first provincial law prohibiting spitting in public places, which aimed to change uncivilized behaviors and prevent the spread of infectious diseases [22, 23]. Unlike physical distancing and handwashing that were widely recommended by public health authorities' sources, public spitting messages were mostly from non-official online sources. Another explanation for a decrease in this behavior is 
Table 2 Comparing health-related behaviors before and after the COVID-19 outbreak

\begin{tabular}{|c|c|c|c|c|c|c|}
\hline $\begin{array}{l}\text { Health-related } \\
\text { behaviors }\end{array}$ & Description & $\begin{array}{l}\text { Before the } \\
\text { COVID-19 } \\
\text { break }\end{array}$ & out- & $\begin{array}{l}\text { After the } \\
\text { COVID-19 } \\
\text { break }\end{array}$ & out- & $P$ value \\
\hline $\begin{array}{l}\text { Wearing face } \\
\text { masks }\end{array}$ & $\begin{array}{l}\text { When people had a cold or fever, they would always wear a face mask if } \\
\text { they went outside of their house or apartment }\end{array}$ & \multicolumn{2}{|c|}{$\begin{array}{l}\text { Sample } \\
\qquad(N=2551)\end{array}$} & \multicolumn{2}{|c|}{$\begin{array}{l}\text { Sample } \\
\qquad(N=2551)\end{array}$} & $<0.001 *$ \\
\hline Yes & & 1156 & 45.3 & 2543 & 99.7 & \\
\hline No $\stackrel{\ddagger}{*}$ & & 1395 & 54.7 & 8 & 0.3 & \\
\hline $\begin{array}{l}\text { Practicing } \\
\text { physical } \\
\text { distancing }\end{array}$ & $\begin{array}{l}\text { When people used public transportation or were inside a building and } \\
\text { noticed that someone else seemed to have a cold or a fever (coughing, } \\
\text { sneezing, etc.), they would change their location or try to get away } \\
\text { from others }\end{array}$ & & & & & $<0.001 *$ \\
\hline Yes & & 1830 & 71.7 & 2481 & 97.3 & \\
\hline No & & 721 & 28.3 & 70 & 2.7 & \\
\hline & & Mean & $S D$ & Mean & $S D$ & \\
\hline Washing hands & $\begin{array}{l}\text { The average number of times that people washed their hands daily with } \\
\text { soap (or hand sanitizer) and running water }\end{array}$ & 5.0 & 4.6 & 7.7 & 7.0 & $<0.001 *$ \\
\hline Spitting & $\begin{array}{l}\text { The average number of times that people spat on the ground weekly in } \\
\text { public places }\end{array}$ & 0.4 & 1.7 & 0.1 & 0.9 & $<0.001 *$ \\
\hline Going outside & $\begin{array}{l}\text { The average number of times that people went outside weekly of their } \\
\text { house or apartment }\end{array}$ & 6.1 & 5.2 & 2.2 & 3.0 & $<0.001 *$ \\
\hline Taking shower & The average number of times that people took a shower weekly & 3.7 & 2.2 & 3.7 & 2.4 & 0.45 \\
\hline
\end{tabular}

$\$ 423$ participants, who reported that they sometimes wore a face mask, sometimes did not, were categorized into this group

*Variables that have been significant at 0.05 level

that people remained inside more and such public spitting opportunities were less. These findings do not appear to be driven by social desirability response since other hygienic measures that were not suggested in governmental and public sources, like showering, were not impacted.

Anxiety levels were high in this large sample. A prior survey conducted in China (February) [24], and other surveys conducted in Italy (March) [26], Saudi Arabia (April) [27], Turkey (April) [28], and Germany (MarchMay) [25] have shown that the prevalence of anxiety increased significantly with the global escalation of the COVID-19 pandemic. For example, prior to the COVID-19 outbreak, the prevalence of anxiety among a national sample of 38,294 Chinese urban dwellers was $5.3 \%$ [29], and in a post-COVID survey of 7236 Chinese citizens [24], the prevalence rose to $35.1 \%$ using the same GAD screening instrument. Our study had a similar prevalence to the other, but we identified more factors that were correlated with GAD. Unlike the other survey that found younger age $(<35$ years $)$ and time spent ( $>3$ hours daily) focusing on COVID-19, our assessment of urban dwellers found that GAD was correlated with being a healthcare worker, living in region more profoundly impacted by COVID-19, having poorer self-perceived health status, having a college education, and having moderate to severe depression.

Findings from our urban study, combined with those from both urban and non-urban dwellers, underscore the importance of providing support to a large number of people impacted by a new and evolving epidemic. Our findings, however, provide important insights into how to focus such intervention efforts to provide traumainformed care. For example, healthcare workers, which have been identified elsewhere to experience exceptional levels of stress, should be targeted for screening and intervention. Additionally, those with lower selfperceived health should be targeted. Many such individuals may potentially have comorbid conditions that increase their likelihood of experiencing more severe COVID-19 disease if they become infected [30, 31]. This is especially true since they may perceive they are unable to access needed healthcare services during the pandemic when only essential medical visits were allowed. This could lead them to feel they are left without support to self-manage their medical conditions. While patients with 
Table 3 Bivariate and multivariate correlates of having symptoms of generalized anxiety disorder $(N=2551)$

\begin{tabular}{|c|c|c|c|c|c|c|c|}
\hline \multirow[t]{2}{*}{ Variable } & \multirow[t]{2}{*}{$N$} & \multicolumn{3}{|c|}{ Bivariate associations } & \multicolumn{3}{|c|}{ Multivariate analysis } \\
\hline & & $O R$ & $95 \% C I$ & $P$ value & $a O R$ & $95 \% C I$ & $P$ value \\
\hline Age (years; continuous) & 2551 & 1.0 & $0.99,1.00$ & 0.22 & & & \\
\hline $\operatorname{Sex}$ & 2551 & & & & & & \\
\hline Female & 1758 & 1.05 & $0.89,1.25$ & 0.57 & & & \\
\hline Male (ref) & 793 & & & & & & \\
\hline Educational level & 2551 & & & & & & \\
\hline College degree or above & 2284 & 1.35 & $1.03,1.76$ & $0.03 *$ & 1.38 & $1.03,1.86$ & $0.03 * *$ \\
\hline High school or below (ref) & 267 & & & & & & \\
\hline Marital status & 2551 & & & & & & \\
\hline Married ${ }^{*}$ & 1281 & 1.13 & $0.97,1.32$ & 0.13 & & & \\
\hline Single (ref) & 1270 & & & & & & \\
\hline Self-perceived health status & 2551 & & & & & & \\
\hline Not good & 642 & 1.69 & $1.41,2.02$ & $<0.01 *$ & 1.54 & $1.27,1.87$ & $<0.01 * *$ \\
\hline Good (ref) & 1909 & & & & & & \\
\hline Healthcare worker & 2551 & & & & & & \\
\hline Yes & 408 & 1.56 & $1.26,1.93$ & $<0.01^{*}$ & 1.58 & $1.23,2.02$ & $<0.01 * *$ \\
\hline No (ref) & 2143 & & & & & & \\
\hline Annual income & 2551 & & & & & & \\
\hline$\geq 12$ times of the international poverty threshold & 862 & 1.21 & $0.98,1.50$ & $0.08^{*}$ & 0.98 & $0.76,1.26$ & 0.89 \\
\hline $9-12$ times & 502 & 1.29 & $1.01,1.64$ & $0.04 *$ & 1.16 & $0.89,1.51$ & 0.29 \\
\hline $6-9$ times & 583 & 1.27 & $1.01,1.61$ & $0.04 *$ & 1.14 & $0.88,1.47$ & 0.31 \\
\hline$<6$ times $(\mathrm{ref})$ & 604 & & & & & & \\
\hline From regions with different density of COVID-19 cases & 2551 & & & & & & \\
\hline Hubei $(\geq 10,000$ cases $)$ & 581 & 2.03 & $1.52,2.71$ & $<0.01 *$ & 2.13 & $1.54,2.95$ & $<0.01 * *$ \\
\hline 2nd highest region (1000-9999 cases) & 680 & 1.12 & $0.84,1.49$ & 0.44 & 1.11 & $0.81,1.52$ & 0.51 \\
\hline 3rd highest region (100-999 cases) & 988 & 1.11 & $0.85,1.45$ & 0.45 & 1.18 & $0.88,1.59$ & 0.27 \\
\hline Low density region (1-99 cases; ref) & 302 & & & & & & \\
\hline Living alone & 2551 & & & & & & \\
\hline Yes & 177 & 1.37 & $1.01,1.86$ & $0.04 *$ & 1.02 & $0.73,1.44$ & 0.89 \\
\hline No (ref) & 2374 & & & & & & \\
\hline Measures taken to control COVID-19 in your community & 2551 & & & & & & \\
\hline Very strict & 1249 & 1.24 & $0.31,5.00$ & 0.76 & & & \\
\hline Strict & 1133 & 1.44 & $0.36,5.78$ & 0.61 & & & \\
\hline Fairly strict & 160 & 1.64 & $0.40,6.77$ & 0.50 & & & \\
\hline Loose (ref) & 9 & & & & & & \\
\hline \multicolumn{8}{|l|}{ Traveled after the COVID-19 outbreak } \\
\hline Yes & 116 & 1.46 & $1.00,2.12$ & $0.05^{*}$ & 1.34 & $0.89,2.03$ & 0.16 \\
\hline No (ref) & 2435 & & & & & & \\
\hline In quarantine & 2551 & & & & & & \\
\hline Yes & 219 & 1.38 & $1.04,1.82$ & $0.02 *$ & 1.31 & $0.97,1.77$ & 0.08 \\
\hline No (ref) & 2332 & & & & & & \\
\hline Depression & 2551 & & & & & & \\
\hline Yes & 381 & 6.29 & $4.88,8.09$ & $<0.01^{*}$ & 6.03 & $4.66,7.81$ & $<0.01 * *$ \\
\hline No (ref) & 2170 & & & & & & \\
\hline
\end{tabular}


Table 3 (continued)

\begin{tabular}{|c|c|c|c|c|c|c|c|}
\hline \multirow[t]{2}{*}{ Variable } & \multirow[t]{2}{*}{$N$} & \multicolumn{3}{|c|}{ Bivariate associations } & \multicolumn{3}{|c|}{ Multivariate analysis } \\
\hline & & OR & $95 \% C I$ & $P$ value & $a O R$ & $95 \% C I$ & $P$ value \\
\hline Wearing face masks ${ }^{A}$ & 2551 & & & & & & \\
\hline Yes & 2543 & 0.67 & $0.17,2.70$ & 0.58 & & & \\
\hline No (ref) & 8 & & & & & & \\
\hline Wearing face masks ${ }^{\mathrm{B}}$ & 2551 & & & & & & \\
\hline Yes & 1156 & 0.80 & $0.68,0.94$ & $<0.01 *$ & 0.89 & $0.75,1.07$ & 0.21 \\
\hline No (ref) & 1395 & & & & & & \\
\hline Practicing social distancing ${ }^{\mathrm{A}}$ & 2551 & & & & & & \\
\hline Yes & 2481 & 1.08 & $0.66,1.75$ & 0.77 & & & \\
\hline No (ref) & 70 & & & & & & \\
\hline Practicing social distancing ${ }^{\mathrm{B}}$ & 2551 & & & & & & \\
\hline Yes & 1830 & 0.94 & $0.79,1.12$ & 0.50 & & & \\
\hline No (ref) & 721 & & & & & & \\
\hline Washing hands ${ }^{\mathrm{A}}$ (number; continuous) & 2551 & 1.01 & $1.00,1.02$ & $0.05^{*}$ & 1.01 & $0.99,1.02$ & 0.34 \\
\hline Washing hands ${ }^{\mathrm{B}}$ (number; continuous) & 2551 & 1.01 & $1.00,1.03$ & 0.21 & & & \\
\hline Spitting $^{\mathrm{A}}$ (number; continuous) & 2551 & 1.08 & $0.99,1.18$ & 0.11 & & & \\
\hline Spitting $^{\mathrm{B}}$ (number; continuous) & 2551 & 1.02 & $0.98,1.07$ & 0.37 & & & \\
\hline Going outside $^{\mathrm{A}}$ (number; continuous) & 2551 & 1.00 & $0.98,1.03$ & 0.77 & & & \\
\hline Going outside (number; continuous) $^{\mathrm{B}}$ & 2551 & 1.02 & $1.00,1.03$ & $0.04 *$ & 1.01 & $0.99,1.03$ & 0.39 \\
\hline Taking shower ${ }^{\mathrm{A}}$ (number; continuous) & 2551 & 1.04 & $1.01,1.08$ & $0.01 *$ & 0.99 & $0.93,1.06$ & 0.78 \\
\hline Taking shower ${ }^{\mathrm{B}}$ (number; continuous) & 2551 & 1.05 & $1.01,1.09$ & $<0.01 *$ & 1.03 & $0.96,1.11$ & 0.38 \\
\hline
\end{tabular}

OR odds ratio, $a O R$ adjusted odds ratio, $C I$ confidence interval, ref reference group

* In bivariate logistic regression models, those variables whose $P$ value is less than 0.1 were included in the multiple logistic regression

** Variables that have been significant at 0.05 level in multiple logistic regression model

* Participants who divorced or lost spouse were categorized into the category of Married

${ }^{\text {A }}$ Health-related behavior after the COVID-19 outbreak

${ }^{\mathrm{B}}$ Health-related behavior before the COVID-19 outbreak

depression may also experience anxiety symptoms, in our survey, these variables were not collinear, but suggest that such patients have a lower psychological reserve to deal with stress and experienced heightened anxiety symptoms. This finding is born out in our additional analysis that shows depression is highly correlated with moderate to severe anxiety symptoms.

In the initial stage of responding to COVID-19, most healthcare facilities in the outbreak regions shuttered their doors to patients, except for those with urgent needs. Consequently, care was transitioned to telehealth. One potential implication from this survey is that healthcare providers, when providing tele-health to patients with chronic diseases that may heighten risk for more severe consequences of COVID-19, and even those with depression, should screen such patients for GAD and provide supportive counseling, which can effectively be done using tele-health [32].

As pandemics evolve, unscientific ideas may proliferate about how infections can be prevented, treated and cured. In the early stage of COVID-19, rumors of several effective treatments were touted to suppress COVID-19 from unsubstantiated online sources, which in turn generated the public anxiety because everyone wanted the treatments, yet they were unavailable for purchase [33]. Providing accurate health information guided by science is therefore important to mitigate excess anxiety during the pandemic. Unsubstantiated rumors have been found to provoke anxiety and exacerbate mental health during SARS, avian flu, and swine 
flu epidemics [34-36]. In times of crisis, it is even more important to ensure information is accurate and scientifically grounded to ensure that people feel safe. Local governments or community organizations should provide a scientific way for people to verify the accuracy of information. For example, building up an online portal that can be used by users to type and verify information might be something realistic to achieve in the future. In the case of COVID-19, considerable uncertainty existed and in an evolving crisis, conspiracy theories and hyperbole abound which, in turn, perpetuates anxiety [37]. Health information, however, often comes from multiple sources, but should be derived from someone who is respected, has authority, and is trusted by society.

During an infectious pandemic that requires physical distancing, mobile technology may be crucial as a conduit of accurate (and sometimes inaccurate) information $[38,39]$. Such information is more powerful, however, when collaborative learning is used and people can teach each other as long as an expert is there to guide discussion [40]. Collaborative learning in communities, defined as integrating meaningful community engagement with education, instruction, and reflection to promote the capacity of individuals to take collective actions to improve the quality of life, is a key method considered by many international and national bodies to prepare for, respond to, and recover from emergency situations [41, 42]. Mobile technology-based interventions (e.g., telemedicine) could easily be repurposed to promote community learning not only as a dissemination method of accurate information but also to address anxiety, maintain social connectivity while physically distancing, mobilize resources, and support communitybased networks of people in need [43]. For instance, a tele-health visit using video or telephone from local clinicians could screen, motivate, and treat patients and families. Even when stigma about mental illness is common, as it is in China [29], brief motivational enhancement techniques can be deployed as part of trauma-informed care to routinely prevent anxiety and promote mental health. Building such interventions and messages in public forums and giving people an opportunity to discuss how the pandemic is affecting them can provide an open opportunity for assistance. This would be especially crucial in some regions of mainland China where it might be considered "abnormal" or shameful to seek treatment for anxiety. Such individual or public messaging to provide trauma-informed care to individuals with anxiety would minimally include examples to support self-regulation of stressors, prioritize healthy relationships, explain why health restrictions are being made that otherwise limit routine daily activities, visualize what to expect within reason of what is known, and reframe behaviors to account for people not being at their best during times of crisis [44].

It is no surprise that urban dwellers living closest to the epicenter and with the high density of COVID-19 cases (e.g., Hubei) experienced the most anxiety, relative to those in less dense COVID-19 cases. These individuals had the most uncertainty as they were impacted first and had the least amount of accurate information. Such individuals might have also perceived themselves at highest risk, which is similar to our finding that healthcare workers, also at substantial risk, experienced heightened anxiety symptoms. Of note, healthcare workers had an increased association of experiencing mild anxiety symptoms, but not moderate or severe anxiety symptoms. One might expect that such individuals would have the most severe anxiety symptoms because they are at the highest risk for COVID-19 combined with extreme workloads during a heightened crisis management scenario where personal protective equipment and testing were inadequate [45]. One potential explanation is that healthcare workers self-manage life and death situations on a daily basis and have established functional coping mechanisms. Alternatively, data from Wuhan suggested that over half of healthcare workers accessed support services, which may have helped them better deal with anxietyprovoking stressors [46]. Last, the healthcare workers in this survey may not have been those providing the most direct patient care and therefore did not experience the highest levels of anxiety.

Though this large survey assessing responses and anxiety symptoms across a large number of regions of China had many important and new findings, it is not without limitations. First, convenience sampling using WeChat does not make this a fully representative sample and restricts generalizability. Second, though markedly higher levels of generalized anxiety disorders were reported relative to the general population before COVID-19, we could not infer that COVID-19 was causative of the anxiety due to the cross-sectional nature of the survey. Last, some factors that may have contributed to anxiety symptoms may not have been measured, like time spent online seeking COVID-related information or various types of coping mechanism. Future research should more comprehensively study the possible 
negative psychological consequences of various countermeasures to find out the best solution. Finally, this study compared anxiety levels from before the outbreak to March 2020 but did not assess changes in anxiety levels over the entire period of the pandemic. More longitudinal research should be conducted to examine changes in mental health outcomes over the entire pandemic period.

\section{Conclusion}

COVID-19 has had a profound impact on China initially and continues to do so globally. In China, urban residents markedly changed their health behaviors in response to the evolving epidemic. These urban dwellers also experienced profound levels of anxiety, especially those who were living in settings closest to the most profoundly impacted regions by the epidemic and those who were healthcare workers or with poor perceived health, including those with depression. Much has been learned from prior epidemics to guide a traumainformed response, but when physical distancing practices are imposed, innovations in reaching screening, motivating, and treating such individuals at increased risk for anxiety are urgently needed. Technology-based interventions like online collaborative learning environments and tele-health can be used to solve such obstacles to service delivery. Such lessons can be useful as new settings become susceptible to COVID-19 and as secondary outbreaks emerge before an effective vaccine is made widely available.

Supplementary Information The online version contains supplementary material available at https://doi.org/10.1007/s11524020-00498-8.

Acknowledgments We would like to acknowledge National Institute on Drug Abuse for their support to RS (K01DA051346) and FLA (K24DA017072).

\section{Compliance with Ethical Standards}

Ethical Approval The study protocol was approved by the Institutional Review Board of Yale University and received ethical approval from Wuhan University. All procedures performed in studies involving human participants were in accordance with the ethical standards of the institutional and/or national research committee and with the 1964 Helsinki declaration and its later amendments or comparable ethical standards.
Informed Consent Electronic informed consent was obtained from all individual participants included in the study.

\section{References}

1. COVID-19 Dashboard by the Center for Systems Science and Engineering (CSSE) at Johns Hopkins University (JHU). Available at: https://coronavirus.jhu.edu/map.html. Accessed May 13, 2020.

2. Güner R, Hasanoğlu I, Aktaş F. COVID-19: prevention and control measures in community. Turk J Med Sci. 2020;50(Si-1):571-7.

3. Zhang J, Litvinova M, Liang Y, et al. Changes in contact patterns shape the dynamics of the COVID-19 outbreak in China. Science. 2020:eabb8001.

4. Murray SL. Fear and the front line. $N$ Engl J Med. 2020;382(19):1784-5.

5. Organization WH. Mental health and psychosocial considerations during the COVID-19 outbreak. March 18, 2020. Available at: https://www.who.int/docs/defaultsource/coronaviruse/mental-health-considerations. pdf?sfvrsn=6d3578af_2. Accessed 4 June 2020.

6. Jones B. Urban residents in states hit hard by COVID-19 most likely to see it as a threat to daily life. Available at: https://www.pewresearch.org/fact-tank/2020/03/20/urbanresidents-in-states-hit-hard-by-covid-19-most-likely-to-seeit-as-a-threat-to-daily-life/. Accessed 7 June 2020.

7. Galea S, Merchant RM, Lurie N. The mental health consequences of COVID-19 and physical distancing: the need for prevention and early intervention. JAMA Intern Med. 2020;180:817-8.

8. Centers for Disease Control and Prevention. Outbreaks can be stressful. April 30, 2020. Available at: https://www.cdc. gov/coronavirus/2019-ncov/daily-life-coping/managingstress-anxiety.html. Accessed 4 June 2020.

9. National Bureau of Statistics of China. China Statistical Yearbook. Available at: http://www.stats.gov. cn/tjsj/ndsj/2019/indexeh.htm. Accessed June 01,2020, 2020 .

10. National Health Commission of the People's Republic of China. 截至3月15日24时新型冠状病毒肺炎疫情最新情况 [The latest situation of COVID-19 on March 15, 2020]. March 16, 2020. Available at: http://www.nhc.gov. $\mathrm{cn} / \mathrm{xcs} / \mathrm{yqtb} / 202003 / 114113 \mathrm{~d} 25 \mathrm{c} 1 \mathrm{~d} 47 \mathrm{aabe} 68381 \mathrm{e} 836 \mathrm{f06}$ a8.shtml. Accessed 8 June 2020.

11. Ni Z, He J, Wang JG, Cao J, Yang Q, Wu B, et al. Chinese physicians' perspectives on the 2017 American College of Cardiology/American Heart Association Hypertension Guideline: a mobile app-based survey. High Blood Press Cardiovasc Prev. Jun 2019;26(3):247-57.

12. Chen L. Application of "Questionnaire Star" in ideological and political theory courses of higher vocational colleges. The Science Education Article Collects. 2018;03

13. Brislin RW. Back-translation for cross-cultural research. $J$ Cross-Cultural Psych. 1970;1:185-216.

14. Spitzer RL, Kroenke K, Williams JBW, Löwe B. A brief measure for assessing generalized anxiety disorder: the GAD-7. Arch Intern Med. 2006;166(10):1092-7. 
15. Foa EB, Huppert JD, Leiberg S, Langner R, Kichic R, Hajcak G, et al. The obsessive-compulsive inventory: development and validation of a short version. Psychol Assess. 2002;14(4):485-96.

16. Kroenke K, Spitzer RL, Williams JB. The Patient Health Questionnaire-2: validity of a two-item depression screener. Med Care. 2003;41(11):1284-92.

17. Daily CY. 2020年贫困户脱贫收入要达4000元. Available at: http://finance.people.com.cn/n1/2019/0308/c100430964216.html. Accessed 21 Oct 2020.

18. Bank TW. FAQs: Global Poverty Line Update. Available at: https://www.worldbank.org/en/topic/poverty/brief/globalpoverty-line-faq. Accessed 21 Oct 2020.

19. Li Z. 北京市拟提高随地吐痰等行为罚款额度,. Xinhua News Available at: http://www.xinhuanet.com/local/2020-04/24 /c 1125898448.htm. Accessed 19 Aug 2020.

20. Mo He. Hangzhou makes public spitting illegal. Ecns.cn. Available at: http:/www.ecns.cn/cns-wire/2016/02-04 /198385.shtml. Accessed 19 Aug 2020.

21. 津市文明行为促进条例. Available at: http://credit.fzgg.tj.gov. cn/72/22811.html. Accessed August 19, 2020.

22. The People's Government of Shanxi Province. 山西立法禁止 公共场所随地吐痰. Available at: http://www.shanxi.gov. $\mathrm{cn} / \mathrm{yw} / \mathrm{zcjd} / \mathrm{tpjd} / 202005 / \mathrm{t} 20200518$ _801188.shtml. Accessed August 17, 2020.

23. Zhan J. 山西立法禁止公共场所随地吐痰 Available at: http://www.xinhuanet.com/legal/2020-05/16 /c_1125993477.htm. Accessed 17 Aug 2020.

24. Huang Y, Zhao N. Generalized anxiety disorder, depressive symptoms and sleep quality during COVID-19 outbreak in China: a web-based cross-sectional survey. Psychiatry Res. 2020;288:112954-4.

25. Bäuerle A, Teufel M, Musche V, et al. Increased generalized anxiety, depression and distress during the COVID-19 pandemic: a cross-sectional study in Germany. J Public Health (Oxf). Jul 132020.

26. Mazza C, Ricci E, Biondi S, et al. A nationwide survey of psychological distress among Italian people during the COVID-19 pandemic: immediate psychological responses and associated factors. Int J Environ Res Public Health. May 2 2020;17(9).

27. Alkhamees AA, Alrashed SA, Alzunaydi AA, Almohimeed AS, Aljohani MS. The psychological impact of COVID-19 pandemic on the general population of Saudi Arabia. Compr Psychiatry. 2020;102:152192-2.

28. Özdin S, Bayrak Özdin Ș. Levels and predictors of anxiety, depression and health anxiety during COVID-19 pandemic in Turkish society: the importance of gender. Int $J$ Soc Psychiatry. May 8 2020:20764020927051.

29. Yu W, Singh SS, Calhoun S, Zhang H, Zhao X, Yang F. Generalized anxiety disorder in urban China: prevalence, awareness, and disease burden. J Affect Disord. 2018/07/ 01/. 2018;234:89-96.

30. Centers for Disease Control and Prevention. People with certain medical conditions. Available at: https://www.cdc. gov/coronavirus/2019-ncov/need-extra-precautions/peoplewith-medical-conditions.html. Accessed August 06, 2020.

31. Druss BG. Addressing the COVID-19 pandemic in populations with serious mental illness. JAMA Psych. 2020;77: 891-2.
32. Aburizik A, Dindo L, Kaboli P, Charlton M, Dawn K, Turvey C. A pilot randomized controlled trial of a depression and disease management program delivered by phone. $J$ Affect Disord. 2013;151(2):769-74.

33. Wang C, Pan R, Wan X, Tan Y, Xu L, Ho CS, et al. Immediate psychological responses and associated factors during the initial stage of the 2019 coronavirus disease (COVID-19) epidemic among the general population in China. Int J Environ Res Public Health. 2020;17(5):1729.

34. Blakey SM, Reuman L, Jacoby RJ, Abramowitz JS. Tracing "Fearbola": psychological predictors of anxious responding to the threat of Ebola. Cogn Ther Res. 2015/12/01. 2015;39(6):816-25.

35. Sandman PM. Pandemics: good hygiene is not enough. Nature. 2009;459(7245):322-3.

36. Van den Bulck J, Custers K. Television exposure is related to fear of avian flu, an ecological study across 23 member states of the European Union. Eur J Pub Health. Aug 2009;19(4):370-4.

37. Ian Freckelton QC. COVID-19: fear, quackery, false representations and the law. Int J Law Psychiatry. 2020;101611

38. Ni Z, Liu C, Wu B, Yang Q, Douglas C, Shaw RJ. An mHealth intervention to improve medication adherence among patients with coronary heart disease in China: development of an intervention. Int J Nurs Sci. 2018/10/10/. 2018;5(4):322-30.

39. Ni Z, Atluri N, Shaw RJ, Tan J, Khan K, Merk H, et al. Evaluating the feasibility and acceptability of a mobile health-based female community health volunteer program for hypertension control in rural Nepal: cross-sectional study. JMIR mHealth and uHealth. 2020;8(3):e15419-9.

40. Bynander FE, Nohrstedt D, editors. Collaborative crisis management. New York, NY: Routledge; 2020.

41. Preston J, Chadderton C, Kitagawa K, Edmonds C. Community response in disasters: an ecological learning framework. Int J Lifelong Educ. 2015/11/02. 2015;34(6): 727-53.

42. Preston J. Disaster education. New York: Sense; 2012.

43. $\mathrm{Wu} \mathrm{B}$. Social isolation and loneliness among older adults in the context of COVID-19: a global challenge. Global health research and policy. 2020;5:27.

44. Browne D, Roy S, Phillips M, Shamon S, Stephenson M. Supporting patient and clinician mental health during COVID-19: via trauma-informed interdisciplinary systems. Canadian family physician Medecin de famille canadien. 2020;66(7):e190-2.

45. Shanafelt T, Ripp J, Trockel M. Understanding and addressing sources of anxiety among health care professionals during the COVID-19 pandemic. JAMA. 2020;323(21):2133-4.

46. Kang L, Ma S, Chen M, Yang J, Wang Y, Li R, et al. Impact on mental health and perceptions of psychological care among medical and nursing staff in Wuhan during the 2019 novel coronavirus disease outbreak: a cross-sectional study. Brain Behav Immun. Jul 2020;87:11-7.

Publisher's Note Springer Nature remains neutral with regard to jurisdictional claims in published maps and institutional affiliations. 